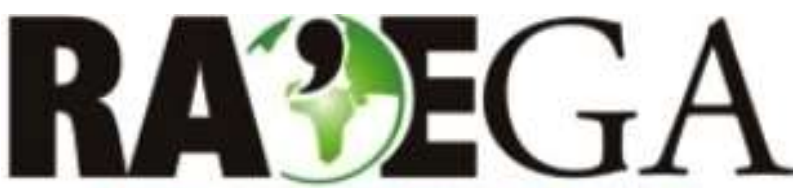

O ESPACO GEOGRÁFICO EM ANÁLISE

\title{
VULNERABILIDADE AOS PROCESSOS EROSIVOS NO LITORAL DO PARANÁ ESTABELECIDO PELA APLICAÇÃO DA ANÁLISE MULTICRITÉRIOS
}

\section{VULNERABILITY TO EROSION ON THE COAST OF PARANÁ ESTABLISHED BY APPLICATION OF MULTI-CRITERIA ANALYSIS}

\author{
Lígia Padilha Novak \\ Universidade Federal do Paraná - UFPR \\ Curitiba, PR, Brasil \\ e-mail: ligianovak@gmail.com \\ Marcelo Renato Lamour \\ Universidade Federal do Paraná - UFPR \\ Curitiba, PR, Brasil \\ e-mail: mlamour@ufpr.br \\ Pâmela Emanuelly Cattani \\ Universidade Federal do Paraná - UFPR \\ Curitiba, PR, Brasil \\ e-mail:pamelacattani@gmail.com
}

Recebido em: 03/09/2015

Aceito em: 13/06/2016

\section{Resumo}

A linha de costa do Paraná, além das interferências naturais, tem sido submetida a intensas modificações antrópicas pela ocupação da orla. Com isso, processos como a erosão costeira passam a ser vistos como um fator de risco. Baseado nestas afirmações este trabalho objetivou o mapeamento da vulnerabilidade a processos erosivos na costa do município de Matinhos, evidenciando áreas críticas ou mesmo em estágio avançado de erosão. Para isso foram identificados indícios de erosão na linha de costa como feições morfológicas com potencial de agravamento de processos erosivos, sangradouros (antrópicos e naturais), obras de proteção costeira e largura do pós-praia. A metodologia utilizada classificou os trechos norte e central do município de Matinhos como menos vulneráveis à erosão. A maior vulnerabilidade foi encontrada nos Balneários Caiobá, Riviera e Flamingo, justamente onde ocorreram as obras de proteção costeira e onde a urbanização apresentou-se mais consolidada. Esta pesquisa gerou resultados 
importantes que poderão ser incorporados nas políticas públicas da zona costeira, apresentando uma metodologia prática com a aplicação de indicadores e uma ferramenta de análise espacial que contribui para estudos de vulnerabilidade à erosão costeira.

Palavras-chave: Ocupação antrópica; transporte sedimentar; análise espacial.

\begin{abstract}
The coastline of the state of Paraná, Brazil, beyond the natural interference, has undergone intense human occupation. Thus, processes such as coastal erosion are seen as risk factors. Based on these statements, this study aims to spatial analysis, focusing environmental issues and identifying critical areas, important for the occupation management, in the municipality of Matinhos. The field work consisted in identifying and locating evidence of erosion on the coastline (width of the shoreline), morphological features considered to favor these processes (natural/anthropogenic washouts), and shoreline protection structures (riprap, walls, stairs). The methodology used in this study classified the northern and central parts of Matinhos as less vulnerable to erosion. The increased vulnerability was found in Caiobá, Riviera and Flamingo beaches, just where the shoreline protection structures were and where urbanization had become more consolidated. This research has led to important results that may be incorporated into the public policies of the coastal zone, with a practical methodology with the application of indicators and a spatial analysis tool that will contribute to vulnerability studies of coastal erosion.
\end{abstract}

Keywords: human occupation, sediment transport, spatial analysis

\title{
1.INTRODUÇÃO
}

Não diferente de outros países, o Brasil apresenta diversas praias onde o processo de erosão é grave, demandando em muitos casos medidas para a sua contenção e/ou recuperação da orla (ESTEVES et al., 1999; KLEIN et al., 1999), o que somente veio a se tornar uma preocupação a partir da década de 1990 (SOUZA et al., 2005; MUEHE, 2006; SOUZA, 2009). Apesar disso, as mudanças naturais na configuração da linha de costa ocorrem em função do transporte de sedimentos transversal e longitudinalmente à costa, principalmente em consequência da dinâmica das ondas, marés, ressacas ${ }^{1}$, runup e setup (BOAK; TURNER, 2005, p. 689).

\footnotetext{
${ }^{1}$ Associação entre frontogêneses que geram agitação marítima acentuada e preamares em condições de sizígia (QUADROS, 2002).

R. Ra'e Ga - Curitiba, v. 38, p.195 - 220 , Dez/2016
} 


\section{VULNERABILIDADE AOS PROCESSOS EROSIVOS NO LITORAL DO PARANÁ ESTABELECIDO PELA APLICAÇÃO DA ANÁLISE MULTICRITÉRIOS}

No geral, a erosão costeira pode ser caracterizada como um processo natural de modificação da linha de costa, que do ponto de vista geológico é decorrente de um suprimento negativo de sedimentos. Sob o ponto de vista da gestão, apresenta conflitos pelo antagonismo frequente entre a dinâmica costeira e a ocupação urbana motivada tanto pela especulação imobiliária como por problemas sociais (ocupação irregular). Neste contexto, ambientes como as restingas no mais amplo sentido que o termo possa designar (SOUZA et al., 2008), são pressionados em ambas as extremidades pois por um lado tendem a serem consumidas pela erosão e por outro, tendem a serem soterradas ou mesmo pavimentadas pela urbanização.

Muitas vezes, a opção escolhida para a mitigação dos processos erosivos é pelo uso de obras costeiras (enrocamentos, muros de arrimo, gabiões, etc.), o que acaba por resolver o problema temporariamente e/ou intensificá-lo posteriormente. Neste caso, o comportamento do regime climático em curto prazo, traduzido principalmente na direção e intensidade dos ventos são mais importantes que a variação no nível relativo do mar, já que influenciam diretamente na formação da ondulação que atinge a costa (NEMES; MARONE, 2013).

As praias da costa litorânea do estado do Paraná são predominantemente arenosas, sem a ocorrência frequente de pontais rochosos. A faixa de restinga ${ }^{2}$ é bastante extensa, principalmente na sua porção norte em contraponto da porção sul onde ocorrem os principais adensamentos populacionais. De acordo com Pierri et al. (2006, p.160), a urbanização deste trecho do litoral brasileiro ocorreu na forma de loteamentos paralelos próximos ou mesmo sobre a praia. O principal efeito desta ação pode ser observado no litoral centro sul do Paraná, onde houve destruição das dunas frontais, aterramento de brejos e reconfiguração de rios e córregos (ANGULO, 1993).

\footnotetext{
${ }^{2}$ Depósito arenoso subaéreo produzido por dinâmica costeira onde se desenvolve vegetação herbácea e arbustiva (SOUZA et al., 2008, p.43).
}

R. Ra'e Ga - Curitiba, v. 38, p.195 - 220 , Dez/2016 


\section{VULNERABILIDADE AOS PROCESSOS EROSIVOS NO LITORAL DO PARANÁ ESTABELECIDO PELA APLICAÇÃO DA ANÁLISE MULTICRITÉRIOS}

Com isso, áreas costeiras de interesse ambiental e socioeconômico merecem atenção dos atores envolvidos na sua gestão, principalmente quando a erosão se torna severa e/ou permanente ao longo do ambiente praial, tornando-se assim um risco ${ }^{3}$ (SOUZA et al., 2005). Parte desta preocupação advém da perda de território de áreas de preservação permanente (APPs) como as restingas e também, pelo risco de perda econômica das edificações localizadas na orla costeira. Ademais, no âmbito das ditas mudanças climáticas globais e seus efeitos, a faixa costeira tende a ser a principal área afetada por eventuais mudanças no contexto do nível relativo do mar.

Desta forma, a observação pontual de fenômenos climáticos e as suas relações com as intervenções humanas é fundamental no entendimento dos processos globais. Assim, o principal objetivo deste trabalho foi estabelecer 0 papel de forçantes ambientais (natural e antrópica) sobre as modificações da costa, delimitando a vulnerabilidade ${ }^{4}$ da orla quanto à erosão por técnicas de relação espacial.

\section{2. ÁREA DE ESTUDO}

A planície costeira do estado do Paraná formou-se pelas oscilações do nível relativo do mar (NRM) ao longo do Período Quaternário, a qual se estende entre o sopé da Serra do Mar até as praias banhadas pelo oceano Atlântico (ANGULO, 2004, p.30). As oscilações sucessivas do NRM produziram uma infinidade de feições costeiras, das quais podem ser destacados os cordões litorâneos (BIGARELLA, 1946, p.66), que apresentam sucessões entre cristas e depressões, constituindo áreas alagadas e pequenas lagoas (ANGULO, 2004, p.39), as quais ao desembocarem nas praias formam cursos de água na forma de sangradouros. A batimetria da plataforma continental interna do Paraná varia entre os 5 e os 15 m (VEIGA et. al., 2004, p.68), onde o

\footnotetext{
${ }^{3}$ Entende-se como risco a probabilidade de consequências prejudiciais, tanto econômicas e/ou sociais resultado da interação de perigos naturais e ações antrópicas num ambiente (UN/ISDR, 2004,16).

4 Vulnerabilidade é um conceito intrínseco ao conceito de risco. Refere-se ao conjunto de condições determinadas por fatores físicos, sociais, econômicos que aumentam a suscetibilidade de uma comunidade a um evento perigos (UN/ISDR, 2004, p.16). 
VULNERABILIDADE AOS PROCESSOS EROSIVOS NO LITORAL DO PARANÁ ESTABELECIDO PELA APLICAÇÃO DA ANÁLISE MULTICRITÉRIOS

talude é suave pela ausência de grandes obstáculos rochosos para a propagação das ondas em direção da costa.

A região litorânea paranaense é caracterizada por um regime de micromarés de amplitude de 1,5 m (MARONE et al., 1995). A direção de propagação de ondas na plataforma interna é SSE, sendo dominada por ondas de alta frequência formadas por ventos próximos à costa, gerados pelas frontogêneses e ciclones subtropicais em fase inicial (NEMES, 2011, p. 122). A corrente de deriva longitudinal flui com sentido NE (BIGARELLA et al., 1978), evidenciado pela orientação das desembocaduras dos rios e pela morfologia dos deltas de maré vazante dos estuários de Guaratuba e Paranaguá (ANGULO, 1992).

Os ventos mais intensos que atingem a costa a partir do quadrante $S$ possuem um giro sazonal de E-SE-S e atuam com maior intensidade entre os meses de junho e agosto, ocasionado pela maior ação das frontogêneses e no restante dos meses do ano há predominância de ventos de $E$ e SE (OLIVEIRA; DOURADO, 2010). A pluviometria subdivide-se em uma estação típica de chuva entre o final da primavera e do verão, e uma estação seca compreendida entre outono e inverno, usualmente interrompida por um curto e fraco período de chuva no início do inverno (LANA et al., 2001).

O arco praial que está contido pelos limites políticos do município de Matinhos apresenta orientação NE-SW em sua maior parte, sendo interrompidos por um único pontal rochoso denominado de Pedra de Matinhos. Os sedimentos praiais são constituídos por areias finas a médias bem selecionadas, com predomínio de grau de assimetria negativa (ANGULO, 1992). Segundo Quadros (2002), o estado morfodinâmico destas praias é dissipativo, apresentando comportamento intermediário e refletivo em alguns trechos do litoral, como no balneário Praia de Leste.

O município de Matinhos possui uma área de $118 \mathrm{~km}^{2}$ onde uma população de 29.428 habitantes reside (IBGE, 2010), contudo em períodos de veraneio e/ou feriados este número aumenta de sobremaneira, apesar da falta de uma estimativa oficial para esta população flutuante. Esta área é reconhecida por diversos autores (ANGULO, 1993; ANGULO; ARAÚJO, 1996; 
VULNERABILIDADE AOS PROCESSOS EROSIVOS NO LITORAL DO PARANÁ ESTABELECIDO PELA APLICAÇÃO DA ANÁLISE MULTICRITÉRIOS

ANGULO; SOARES, 1994) como um hotspot erosivo no litoral do Paraná, onde os custos para a manutenção da orla oneram os cofres públicos.

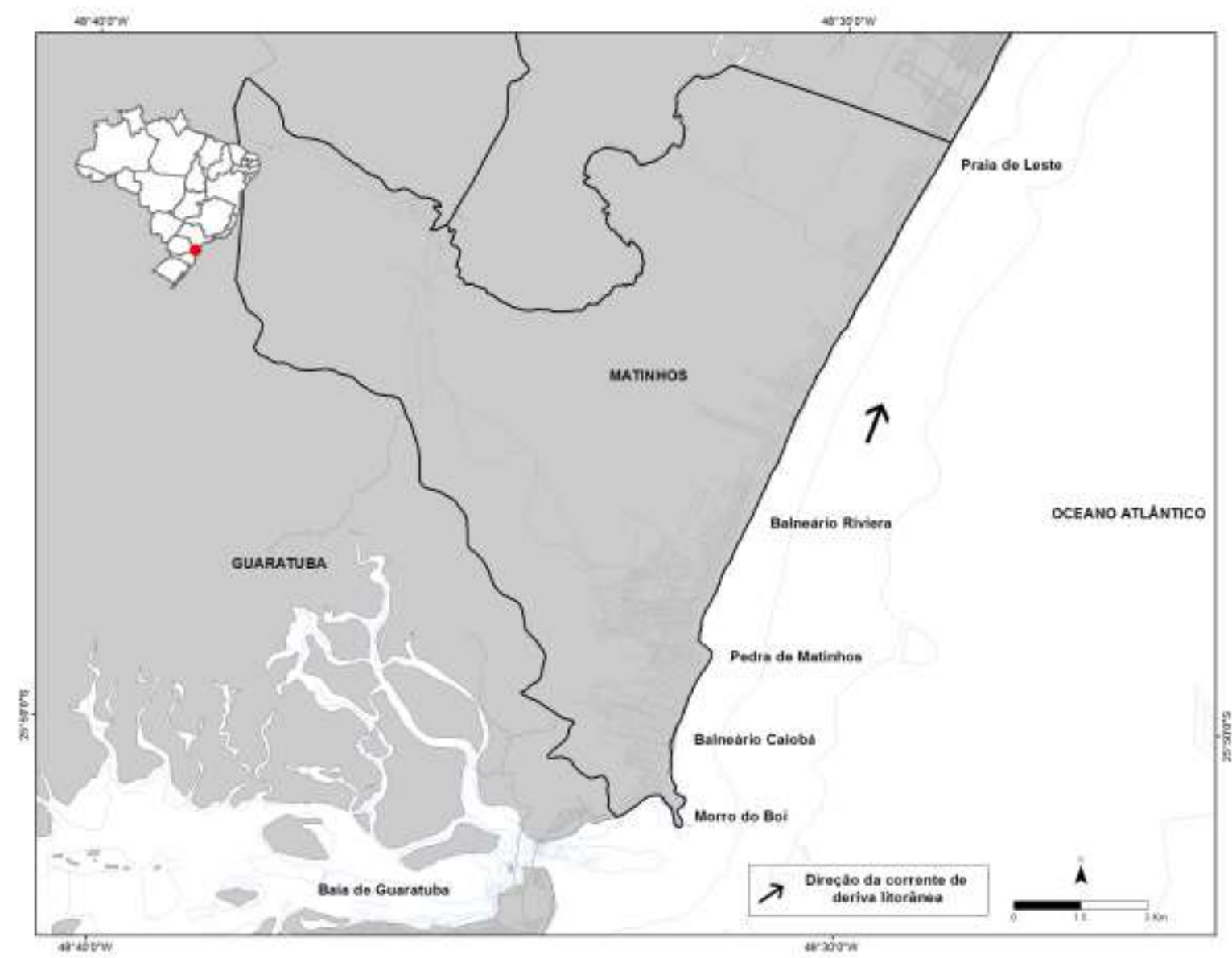

Figura 1: Mapa de localização da área de estudo com a posição dos principais balneários sob a influência dos processos erosivos.

\section{MATERIAIS E MÉTODOS}

As características granulométricas atuais dos sedimentos praiais foram estabelecidas a partir da amostragem de 32 pontos superficiais ao longo da linha de água, com espaçamento de 500 metros entre si. Essas amostras foram preparadas para a análise pela eliminação dos carbonatos $\left(\mathrm{CO}_{3}\right)$ com ataque químico de ácido clorídrico $(\mathrm{HCl})$ diluído em 10\%. Nesta oportunidade, também foram quantificadas as suas porcentagens nos sedimentos, pela comparação de pesos antes e depois do ataque. 


\section{VULNERABILIDADE AOS PROCESSOS EROSIVOS NO LITORAL DO PARANÁ ESTABELECIDO PELA} APLICAÇÃO DA ANÁLISE MULTICRITÉRIOS

O passo seguinte foi a submissão destas amostras à análise granulométrica por dispersão laser, onde foi utilizado o granulômetro a laser BlueWave (Microtrac), o qual estabeleceu os parâmetros estatísticos granulométricos pelo método descrito por Folk e Ward (1964) (Diâmetro médio, Grau de seleção e Assimetria). Posteriormente, estes resultados foram também utilizados na identificação da dinâmica sedimentar da área pela aplicação dos métodos GSTA (Grain Size Trend Analysis; GAO; COLLINS, 1992) e GSTAST (Grain Size Trend Analysis with Significance Test; CHANG et al., 2001) pelos quais foram estabelecidos vetores de tendências de transporte sedimentar residual, para a identificação das células de circulação costeira.

O grau de erosão na linha de costa foi analisado pela observação, descrição e localizações dos indícios descritos por Souza (1997) e Souza et al. (2005). Ainda foram identificadas e registradas outras feições reconhecidas como potencializadoras dos processos erosivos como: 1. Sangradouros (naturais e antrópicos); 2. Desembocaduras (rios e gamboas); 3. Galerias de escoamento pluvial; 4. Estruturas de proteção costeira (enrocamentos, muros, gabiões e escadarias); 5. Grau de urbanização da orla, e 6. Largura do PósPraia.

As análises espaciais foram estabelecidas com base em pesos atribuídos a cada uma das variáveis analisadas, conforme a sua relação negativa (1) ou positiva (2) com o risco gerado pela erosão costeira. A integração e a análise espacial dos dados foram realizadas no software ArcGis 10.1, seguindo a proposta de Lamour et al. (em prep.). Inicialmente foram criados polígonos arbitrários com largura de 500 metros costa adentro a partir da linha de costa, pela necessidade de uma mesma área de comparação entre cada um dos indicadores analisados, auxiliando na integração espacial.

Posteriormente, dentro dos polígonos, foi criada uma grade de malha regular de 50 metros de lado (pixels) destinada à análise espacial dos dados, tomando como base as coordenadas de seus centroides, possibilitando a integração dos parâmetros pela técnica de álgebra entre mapas. Os dados integrados foram transformados em formato imagem (rasterizados), para a elaboração dos mapas. A vulnerabilidade à erosão costeira foi dividida em 2 
classes: alta e baixa. A classificação alta correspondeu aos pesos igual a 2 e baixa aos pesos igual a 1 .

Por fim, foram realizadas cinco relações espaciais entre os indicadores analisados com objetivo de obter uma representação integrada na avaliação da vulnerabilidade à erosão costeira.

\subsection{ANÁLISES E SEUS CRITÉRIOS}

Os sangradouros receberam a classificação pelo seu grau de adensamento, onde a relação com os pesos atribuídos foi diretamente proporcional. Assim como para os sangradouros, foi atribuído às galerias pluviais peso 2 onde estavam mais concentradas, e peso 1 onde havia redução da sua concentração ou mesmo quando não foram observadas em campo. Essa atribuição de pesos foi assim definida, pois, nos locais onde há maior concentração de galerias, há mais pontos de escoamento de águas pluviais, portanto formam maior número de sangradouros. Esta escolha foi embasada pelas constatações de Figueiredo e Calliari (2005) de que em áreas balneárias aumenta a ocorrência de sangradouros não naturais, pois com o avanço da urbanização e a decorrente pavimentação urbana diminuem a área de infiltração, sendo essas águas extravasadas para a praia na forma de sangradouros.

A largura do pós-praia, contido entre as obras costeiras e a linha de vegetação, foi utilizada como critério para a determinação da vulnerabilidade da linha de costa aos processos erosivos. Neste processo de delimitação da largura do pós-praia preservado em cada setor da área de estudo, as medidas foram tomadas em fotografias aéreas relativas ao ano de 2003 (ITCG, 2014), pois são as mais recentes disponíveis na região. O peso maior foi atribuído arbitrariamente a larguras menores que os $30 \mathrm{~m}$, enquanto que o menor peso a larguras maiores que os $30 \mathrm{~m}$.

Como não se constataram diferenças significativas entre as obras costeiras presentes nos balneários, na definição das influências de cada tipo de 
obras costeiras considerou-se o critério de presença e ausência, atribuindo peso maior ou menor, respectivamente.

O critério de classificação para a urbanização foi baseado na proposta do Projeto Orla (2006), onde as áreas em processo de urbanização apresentam indícios de ocupação recente, com paisagens parcialmente antropizadas, podendo ocorrer atividades tradicionais, como pesca artesanal. Ainda puderam ser caracterizadas pela predominância de segundasresidências e volume de população não residente. Já orlas com urbanização consolidada apresentam paisagens altamente modificadas pela ação humana, alto adensamento de construções e população e também grande potencial de poluição sanitária. Portanto, orlas com urbanização consolidada tiveram relação positiva e orlas em processo de urbanização apresentam relação negativa.

Para o diâmetro médio do grão, a atribuição dos pesos foi baseada no estudo Figueiredo e Calliari (2005) que verificaram que as areias finas apresentam uma relação positiva para a ocorrência de sangradouros. Portanto, nos trechos onde ocorreram as areias finas atribuiu-se maior peso e onde se encontravam areias médias menor peso.

Alves (2011) constatou que nas zonas de divergência entre vetores de transporte sedimentar, as regiões apresentavam tendência a processos sedimentares deposicionais, e em zonas correspondentes a convergência entre vetores, apresentavam processos sedimentares predominantemente erosivos. Baseado nessas constatações, foi atribuído peso 1 aos vetores que apresentaram comportamento divergente e peso 2 aos vetores convergentes, pelas suas implicações quanto aos processos deposicionais e erosivos, respectivamente. 
VULNERABILIDADE AOS PROCESSOS EROSIVOS NO LITORAL DO PARANÁ ESTABELECIDO PELA APLICAÇÃO DA ANÁLISE MULTICRITÉRIOS

Quadro 1: Sumário dos indicadores de erosão costeira, dos critérios, dos pesos atribuídos e a bibliografia utilizada para embasar a escolha dos pesos (Fonte: Autora).

\begin{tabular}{|c|c|c|c|}
\hline INDICADORES & CRITÉRIOS & PESOS & $\begin{array}{c}\text { EMBASAMENTO } \\
\text { TEÓRICO }\end{array}$ \\
\hline \multirow[b]{2}{*}{ Urbanização } & Orla em urbanização & 1 & \multirow{2}{*}{ Projeto Orla (2006) } \\
\hline & Orla urbanizada & 2 & \\
\hline \multirow{2}{*}{ Obras Costeiras } & $\begin{array}{c}\text { Baixa concentração ou } \\
\text { ausência }\end{array}$ & 1 & \multirow{2}{*}{$\begin{array}{c}\text { Souza (1997);Souza et } \\
\text { al. (2005) }\end{array}$} \\
\hline & Alta concentração & 2 & \\
\hline \multirow[b]{2}{*}{ Pós-praia } & Largura $0-70$ & 1 & \multirow{2}{*}{$\begin{array}{c}\text { Souza (1997); Souza et } \\
\text { al. (2005) }\end{array}$} \\
\hline & Largura $0-30$ & 2 & \\
\hline \multirow{2}{*}{ Galerias Pluviais } & $\begin{array}{c}\text { Baixa concentração ou } \\
\text { ausência }\end{array}$ & 1 & \multirow{2}{*}{$\begin{array}{l}\text { Figueiredo e Calliari } \\
\qquad(2005)\end{array}$} \\
\hline & Alta concentração & 2 & \\
\hline \multirow{2}{*}{ Sangradouros } & $\begin{array}{l}\text { Baixa concentração ou } \\
\text { ausência }\end{array}$ & 1 & \multirow{2}{*}{$\begin{array}{l}\text { Figueiredo e Calliari } \\
\qquad(2005)\end{array}$} \\
\hline & Alta concentração & 2 & \\
\hline \multirow[b]{2}{*}{ Diâmetro Médio } & Areias médias & 1 & \multirow{2}{*}{$\begin{array}{l}\text { Figueiredo e Calliari } \\
\qquad(2005)\end{array}$} \\
\hline & Areias finas & 2 & \\
\hline \multirow{2}{*}{$\begin{array}{l}\text { Vetores de } \\
\text { tendência }\end{array}$} & $\begin{array}{l}\text { Transporte Longitudinal e } \\
\text { divergência de vetores }\end{array}$ & 1 & \multirow{2}{*}{ Alves (2011) } \\
\hline & Convergência de vetores & 2 & \\
\hline
\end{tabular}

\section{RESULTADOS}

Foram contabilizadas 106 galerias de escoamento de águas pluviais, com distância média de 90 metros entre elas. Estas se apresentaram com uma densidade maior nas áreas norte e central do que na área ao sul, entretanto nos trechos adjacentes ao Rio Matinhos e na porção norte do Balneário Caiobá não foram observadas galerias pluviais.

Seguindo da área norte até a central, a largura do pós-praia variou entre os 30 e 70 metros, contudo na porção sul do Balneário Caiobá a largura média do pós-praia foi de 15 metros. Principalmente nos Balneários Riviera e Flamingo (Figura 5), o pós-praia inexistiu tendo sido substituído por obras de 
proteção costeira. Além disso, notaram-se resquícios de ocupação informal sobre o pós-praia, como ajardinamento com introdução de plantas exóticas, estruturas de acesso à praia e de lazer como calçadas, quadras poliesportivas e quiosques. Esta ocupação informal foi mais comum no trecho central e sul da área de estudo.

Foram identificados 37 sangradouros ao longo da linha de costa, dentre os quais, 35 foram classificados como de origem antrópica, pois estavam relacionados com as galerias de escoamento de águas pluviais. Os demais apresentaram características de origem natural, tendo sido identificados como os rios Matinhos e Caiobá, os quais se estendem planície costeira adentro, se originando nas adjacências e nas vertentes da Serra da Prata. A porção norte da área de estudo apresentou maior número de sangradouros, com distanciamento médio entre eles de aproximadamente 150 metros. Esta região caracterizou-se por apresentar sangradouros de maior porte quando comparados aos sangradouros situados ao sul da área de estudo.

A concentração de sangradouros diminuiu a partir da sua porção central em direção sul onde o distanciamento médio entre eles foi de 500 metros aproximadamente. Notou-se que onde havia diminuição da faixa de restinga e pós-praia os sangradouros tiveram menor extensão e consequentemente estiveram mais próximos às galerias pluviais. Na extremidade sul, a partir do rio Matinhos, o número de sangradouros diminuiu consideravelmente, onde foram identificados apenas quatro deles. De uma maneira geral, os sangradouros observados são efêmeros e possuem vegetação de restinga associada, contudo apenas os sangradouros classificados como naturais foram reconhecidos como de caráter permanente.

As obras de proteção costeira identificadas foram escadarias, muros e enrocamentos, observadas principalmente nos Balneários Flamingo, Riviera e Caiobá. Em Riviera e Flamingo foram identificadas as três estruturas de proteção da costa, enquanto que no Balneário Caiobá constatou-se presença de escadarias e enrocamentos. As escadarias identificadas em Riviera e Flamingo são menores quando comparadas às localizadas na porção norte do Balneário Caiobá, as quais possuem aproximadamente 8 metros de altura. 
Neste mesmo balneário foram identificados enrocamentos, que não apresentaram diferenças estruturais em relação aos encontrados nos outros dois balneários. Esses balneários têm como característica o pós-praia estreito, alguns locais com resquícios de vegetação de restinga arbustiva e gramíneas, dunas frontais de pequeno porte e ou mesmo inexistentes onde são encontradas as obras de proteção costeira.

$\mathrm{Na}$ porção norte da área de estudo observaram-se áreas vegetadas, com poucos lotes sem ocupação até a terceira quadra, a partir da Avenida Beira-mar. No trecho sul verificou-se uma ocupação consolidada, com poucas áreas vegetadas entre as edificações. Com estas observações foi possível classificar a orla em dois tipos de urbanização, sendo o trecho ao norte em processo de urbanização e trecho sul com urbanização consolidada.

O diâmetro médio dos sedimentos atuais variou entre as areias finas $(0,125-0,250 \mathrm{~mm})$ e médias $(0,250-0,500 \mathrm{~mm})$ de bem a muito pobremente selecionadas, segundo a classificação de Wentworth (1922). As areias finas ocorreram em ambas as extremidades do segmento de arco praial (sul e norte) entre os pontos 1-8 e 27-32, enquanto que as areias médias foram observadas na sua porção central, entre os pontos 9-26 (Figura 2). A maioria das amostras de sedimentos apresentou bom selecionamento dos grãos (bem a moderadamente selecionados). No entanto, junto à desembocadura do Rio Matinhos (pontos 9 a 11) e na porção central do segmento de arco (pontos 1822), houve ocorrência de sedimentos pobremente selecionados, com apenas uma ocorrência de sedimentos muito pobremente selecionados (ponto 24) (Figura 3). A assimetria variou de muito positiva a muito negativa, sem apresentar um padrão definido (Figura 4). 
VULNERABILIDADE AOS PROCESSOS EROSIVOS NO LITORAL DO PARANÁ ESTABELECIDO PELA APLICAÇÃO DA ANÁLISE MULTICRITÉRIOS

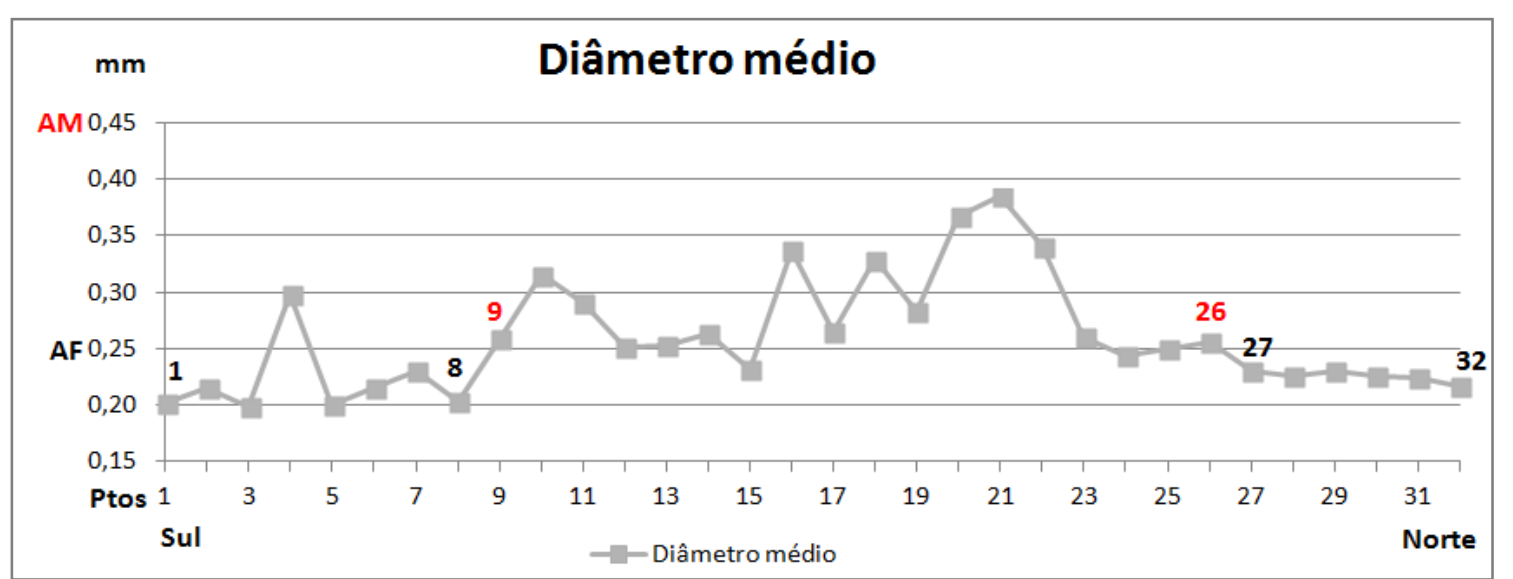

Figura 2: Variação dos valores de diâmetro médio de grão dos sedimentos praiais ao longo do trecho estudado. AF: areia fina; AM: areia média (Fonte: Autora).

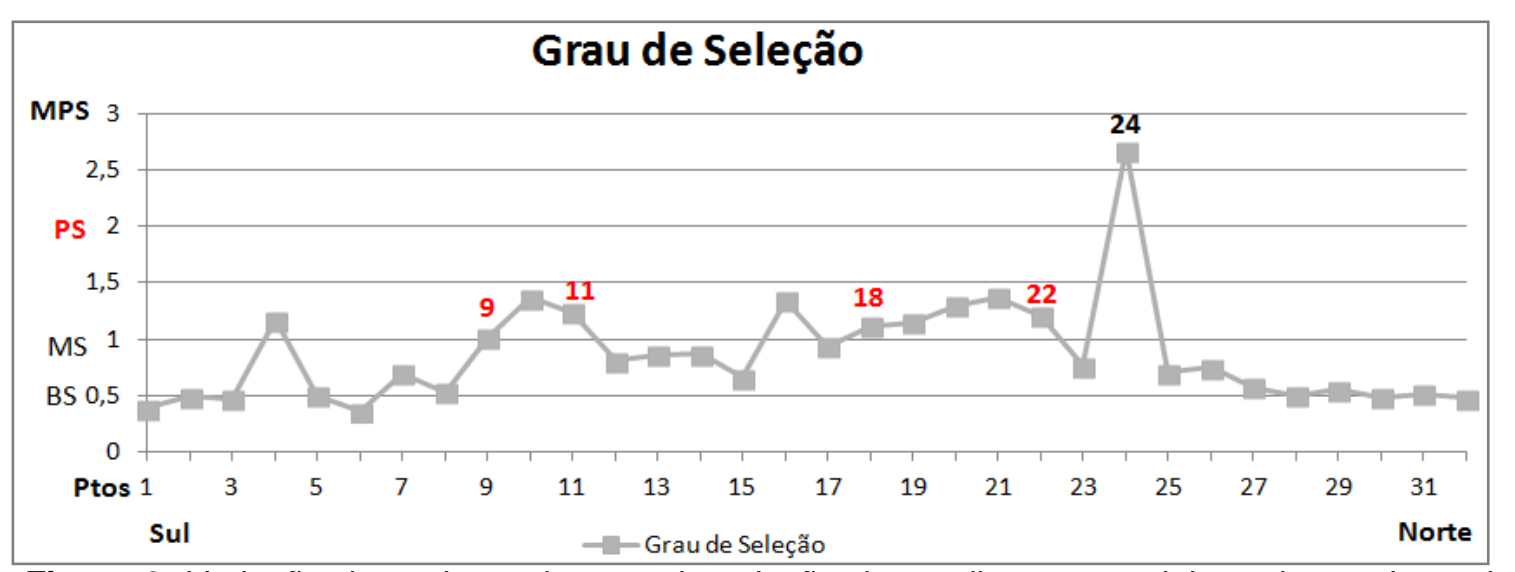

Figura 3: Variação dos valores de grau de seleção dos sedimentos praiais ao longo do trecho estudado. BS: bem selecionado; MS: moderadamente selecionado; PS: pobremente selecionado; MPS: muito pobremente selecionado (Fonte: Autora).

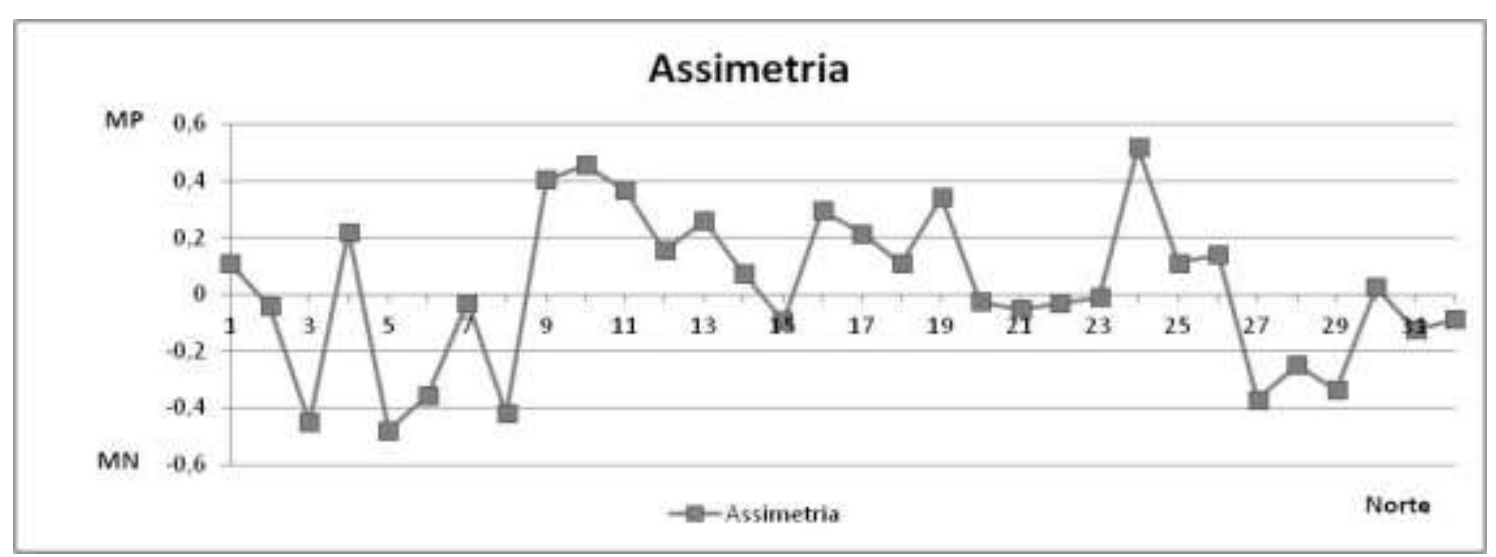

Figura 4: Variação dos valores de grau de assimetria dos sedimentos praiais ao longo do trecho estudado. MP: muito positiva e MN: muito negativa (Fonte: Autora). 

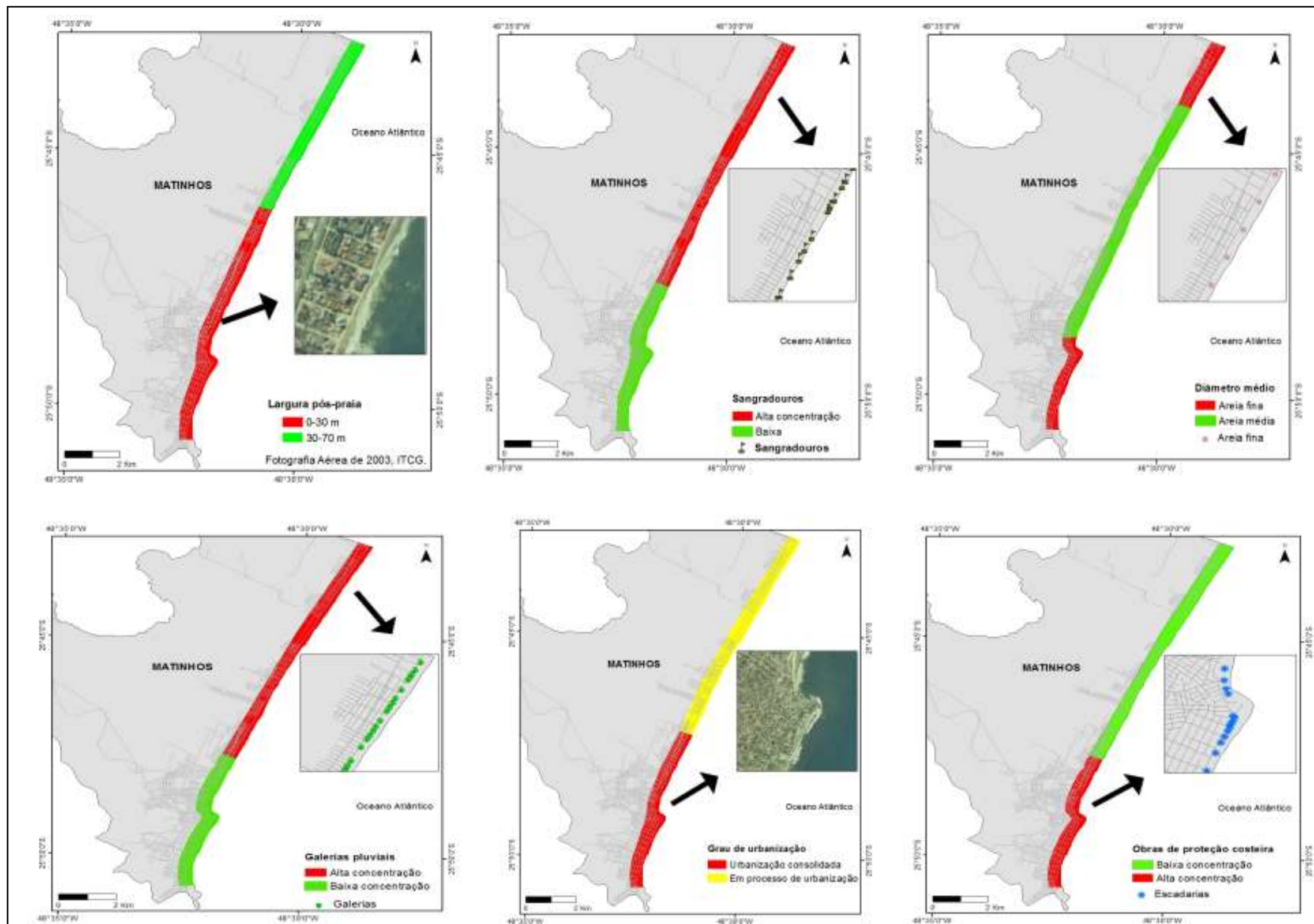


\section{VULNERABILIDADE AOS PROCESSOS EROSIVOS NO LITORAL DO PARANÁ ESTABELECIDO PELA APLICAÇÃO DA ANÁLISE MULTICRITÉRIOS}

A partir do banco de dados das características granulométricas dos sedimentos praiais atuais, foram gerados 36 vetores de tendência de transporte pelo método GSTA, dos quais 10 tiveram um grau de significância acima dos $90 \%$, conforme a análise efetuada pelo método GSTAST. A orientação dos vetores (Figura 5) mostra que na região norte da área de estudo a tendência de transporte residual de transporte é para N, sendo que próximo ao Balneário Caiobá, os vetores indicaram uma orientação oposta.

O padrão de orientação dos vetores teve maior variação próxima à desembocadura do Rio Matinhos e junto à Pedra de Matinhos, onde a sua orientação foi para S-SE. Seguindo de N para S, constatou-se uma zona de divergência de vetores de tendência de transporte sedimentar residual entre os Balneários de Betaras e Flórida. Na região do Balneário de Riviera, por sua vez, observou-se a convergência destes vetores, que podem indicar uma tendência aos processos de erosão.

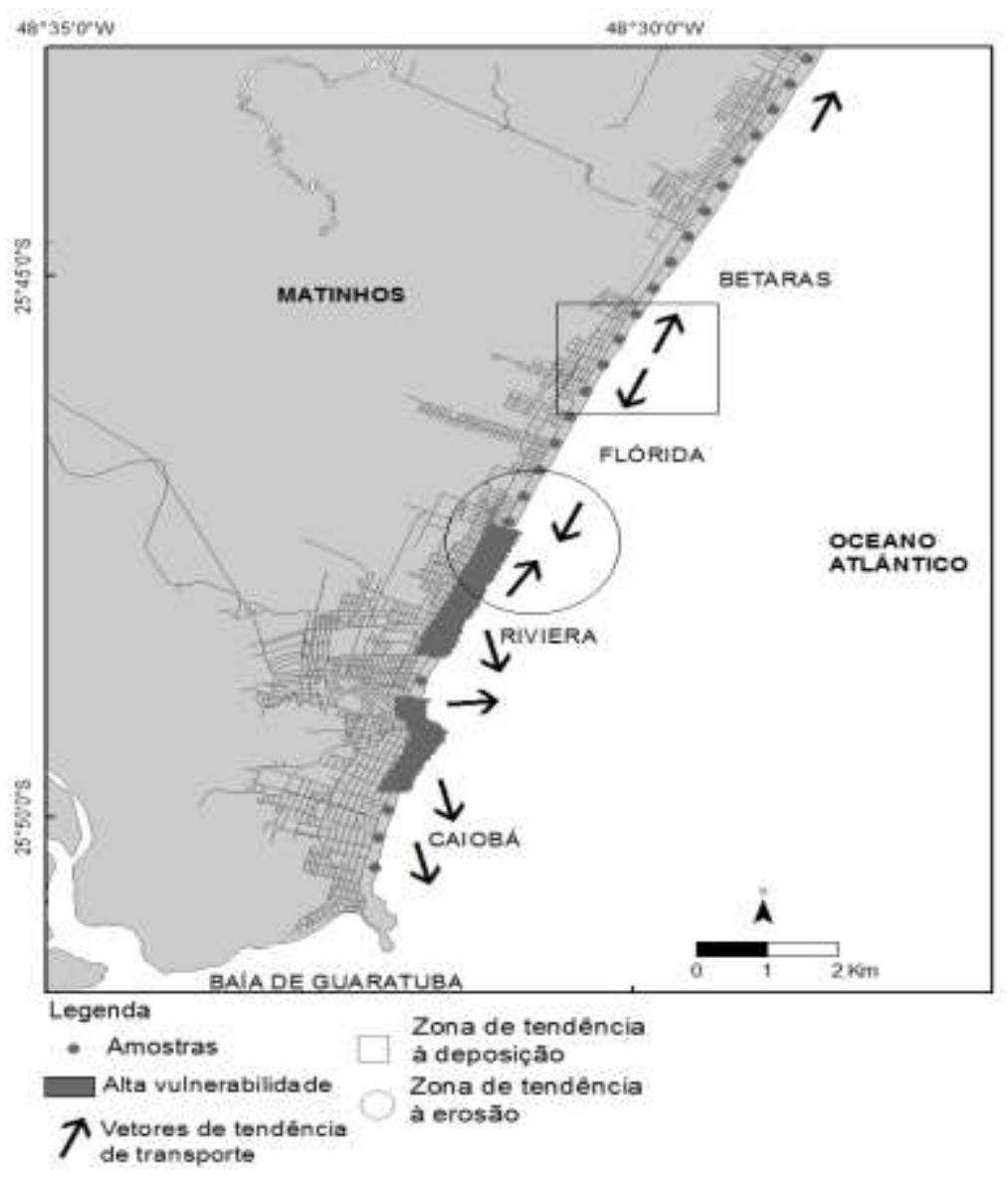


Figura 6: Tendências de transporte sedimentar residual no segmento de arco praial estudado, com destaque para as áreas indicando tendência erosiva (círculo, convergência entre vetores), tendência à deposição (quadrado, divergência entre vetores) e polígonos indicando áreas com erosão severa.

\subsection{RELAÇÕES ESPACIAIS}

Neste contexto, a relação \#1 foi efetuada visando a investigação da capacidade de escoamento superficial das águas continentais em direção a linha de água e os seus efeitos, como o rebaixamento localizado do perfil praial. Os dados incluídos nesta análise foram as galerias pluviais, tamanho médio de grão dos sedimentos praiais e a localização dos sangradouros, onde se concluiu que há uma relação positiva entre estas variáveis.

$\mathrm{Na}$ relação \#2, foi avaliado o potencial erosivo da dinâmica costeira em uma escala regional, no qual foram utilizados os indicadores largura do póspraia, vetores de tendência de transporte residual e obras de proteção da costa, que culminou em uma relação positiva entre as variáveis analisadas. $\mathrm{Na}$ relação \#3, foi analisado o potencial de transporte de sedimentos em uma escala regional pela dinâmica costeira, cujo foram consideradas as variáveis largura do pós-praia, vetores de tendência de transporte e diâmetro médio dos grãos, onde verificou-se uma relação negativa.

A relação \#4 investigou os potenciais de escoamento, erosão e transporte em relação ao grau de urbanização do trecho da costa estudado, sendo observada uma relação positiva entre as variáveis em questão. Nesta relação, a urbanização foi considerada como o indicador de maior importância pelo fato de estar presente ao longo de toda área de estudo, sendo atribuído peso maior e único (2).

Na relação \#5, calculou-se a média ponderada das variáveis analisadas. Cada variável foi avaliada e teve seu peso baseado na sua importância nos processos erosivos, considerando um intervalo de 0 a 1 , no qual valores próximos a 1 possuíam maior importância e valores mais próximo de 0 possuíam menor importância nos processos de erosão. 
A urbanização teve maior peso $(0,8)$ seguido das obras de proteção costeira $(0,5)$, pois estão presentes nos locais onde há severos problemas erosivos. As galerias de escoamento pluvial e os sangradouros receberam o mesmo peso $(0,3)$, pois a grande maioria dos sangradouros estava associada a estas galerias. A largura do pós-praia, diâmetro médio de grão e vetores de tendência de transporte sedimentar receberam o mesmo peso $(0,15)$, pois os vetores de transporte residual e o diâmetro médio dos sedimentos estão associados. Considerou-se que para a geração dos vetores são utilizados os parâmetros granulométricos, que inclui o diâmetro médio, a assimetria e o grau de seleção. Neste caso, a largura do pós-praia é resultado da atuação de processos naturais e antrópicos, por esta razão tal fator recebeu menor peso. As relações feitas estão apresentadas sucintamente no quadro 2.

Posteriormente, foram calculadas (Equação 1) as médias ponderadas dos centroides, o que permitiu o cálculo do valor médio 1,4, que foi utilizado como limite entre ambientes com baixa vulnerabilidade nos valores inferiores a 1,4 e alta vulnerabilidade à erosão para os valores superiores.

(Equação 1)

R5 $=\left(\left(\right.\right.$ urbanização $\left.^{*} 0,8\right)+\left(\right.$ obras $\left.^{*} 0,5\right)+\left(\right.$ pós $\left.^{\left.- \text {praia }^{*} 0,15\right)+(\text { galerias }}{ }^{*} 0,3\right)+$ (sangradouros $\left.{ }^{*} 0,3\right)+\left(\right.$ diâmetro*$\left.^{*} 0,15\right)+\left(\right.$ vetores $\left.\left.^{*} 0,15\right)\right) / 2,35$ 
VULNERABILIDADE AOS PROCESSOS EROSIVOS NO LITORAL DO PARANÁ ESTABELECIDO PELA APLICAÇÃO DA ANÁLISE MULTICRITÉRIOS

Quadro 2: Síntese das correlações e dos indicadores envolvidos na vulnerabilidade à erosão costeira (Fonte: Autora).

\begin{tabular}{|c|c|}
\hline Correlações & Indicadores envolvidos \\
\hline 1. Potencial de escoamento & $\begin{array}{c}\text { Galerias Pluviais } \\
\text { Diâmetro Médio de Grão } \\
\text { Sangradouros }\end{array}$ \\
\hline 2. Potencial de erosão & $\begin{array}{c}\text { Largura do Pós-praia } \\
\text { Vetores de Tendência de Transporte } \\
\text { Obras de Proteção Costeira }\end{array}$ \\
\hline 3. Potencial de transporte & $\begin{array}{c}\text { Largura Pós-praia } \\
\text { Vetores de Tendência de Transporte } \\
\text { Diâmetro Médio de Grão }\end{array}$ \\
\hline 4. Influência antrópica & $\begin{array}{c}\text { Relação } 1 \\
\text { Relação } 2 \\
\text { Relação } 3 \\
\text { Grau de Urbanização }\end{array}$ \\
\hline 5. Dinâmica costeira & $\begin{array}{l}\text { Média Ponderada das variáveis } \\
\text { analisadas }\end{array}$ \\
\hline
\end{tabular}

\section{DISCUSSÃO}

A relação positiva para o potencial de escoamento com a ocorrência das areias finas e sangradouros identificada por Figueiredo e Calliari (2005), pôde ser observada na porção norte da área de estudo (Figura 7). Entretanto, esta não é uma relação geral que pode ser aplicada, já que o fator antrópico quando presente é dominante. Nesta área há uma densidade maior de galerias de escoamento pluvial, sendo que esta configuração pode ser utilizada para explicar a maior ocorrência de sangradouros já que em sua maior parte, são de origem antrópica. Na porção sul, apesar da ocorrência das areias finas, não foram encontrados sangradouros na mesma proporção que na área norte, o que pode ser explicado pela presença do Rio Caiobá, para onde as águas pluviais preferencialmente são drenadas.

Segundo Angulo e Andrade (1982, p.685) a construção da Avenida Beira-mar que ocupou parte do balneário Caiobá e alterou a sua curvatura 
natural, desencadeou um processo erosivo no seu trecho central na década de 1980. Para Muehe (2006, p.3) uma das principais causas da erosão costeira é a interferência antrópica nos processos costeiros seguido da urbanização. Para o mesmo autor, a urbanização em si não promove a erosão, mas sim as construções localizadas dentro da faixa de resposta dinâmica das praias frente às tempestades, que tende a ser retomada pela ação marinha sobre a área construída. Assim sendo, o potencial de erosão pode ser reconhecido pela ação conjugada das forçantes naturais e antrópicas, onde a dinâmica de transporte e as obras costeiras comprimem o pós-praia, no caso do litoral do município de Matinhos, culminando em um avançado processo de erosão.

Entre os Balneários Flamingo e Riviera, estes processos erosivos foram intensificados pela ocupação sobre a faixa de restinga e as dunas, o que fixou a linha de costa na forma de muros e estruturas que sustentam as residências. $\mathrm{Na}$ tentativa de conter o efeito das ondas e das marés, foram utilizados estruturas de proteção longitudinais nestas áreas, como os enrocamentos (ANGULO, 2000, p.99-100). No entanto, estas estruturas apesar de terem a função de proteger a praia contra a ação de ondas, reduzem a área de dissipação de energia das ondas (ESTEVES et al., 1999, p.2), implicando em efeitos nocivos sobre a costa. Isto se reflete em um ciclo vicioso onde a urbanização avança sobre as áreas de acúmulo recente de sedimentos e em contra ponto, a linha de costa tende a restabelecer seu equilíbrio dinâmico culminando nos processos erosivos.

O potencial de transporte mostrou-se menos representativo, pois o trecho que abrange os Balneários Riviera e Flamingo foi apresentado como de baixo potencial, mas que na realidade apresenta um estágio avançado de erosão, com estreitamento do pós-praia. Esta mesma inter-relação apresentou o Balneário Caiobá com uma maior vulnerabilidade à erosão. Neste trecho os vetores de tendência de transporte residual apresentaram uma variação na sua orientação, sem um padrão definido. A presença do pontal rochoso (Pedra de Matinhos) nas proximidades deste Balneário pode explicar a alteração na orientação dos vetores (Figura 7). 
A influência antrópica mostrou-se condizente com o observado em campo, onde a urbanização assumiu importância na análise, pois é uma variável comum a todo trecho em questão e neste estudo foi considerada com elevada importância nos processos erosivos. No trabalho realizado por Nascimento et al. (2013) a urbanização foi um fator determinante para a avaliação da sensibilidade à erosão nas praias da Costa do Cacau na Bahia. Segundo diversos autores (ESTEVES et al., 2000; SCHWARTZ, 2005; BIRD, 1985) a erosão costeira surge como consequência do rápido crescimento e adensamento da população na zona costeira.

A hierarquização dos indicadores apontou trechos que possuem maior adensamento de construções e obras de proteção costeira, como os trechos mais vulneráveis à erosão. Ruddorf e Bonetti (2010, p.17), em estudos realizados nas praias da llha de Santa Catarina, afirmaram que a ocupação inadequada influencia a vulnerabilidade à erosão, pois a presença de estruturas rompe o estoque natural de sedimentos que protege a praia durante eventos de ressaca. Por exemplo, a interferência nesse estoque pode alterar 0 equilíbrio da praia provocando ou intensificando os processos erosivos, e consequentemente a vulnerabilidade. Apesar das praias do Paraná apresentarem uma configuração diferente em relação às praias da llha de Santa Catarina, com menos pontais rochosos e serem mais retilíneas, é possível afirmar que qualquer interferência na forma de edificações sobre a praia irá alterar a dinâmica praial. 

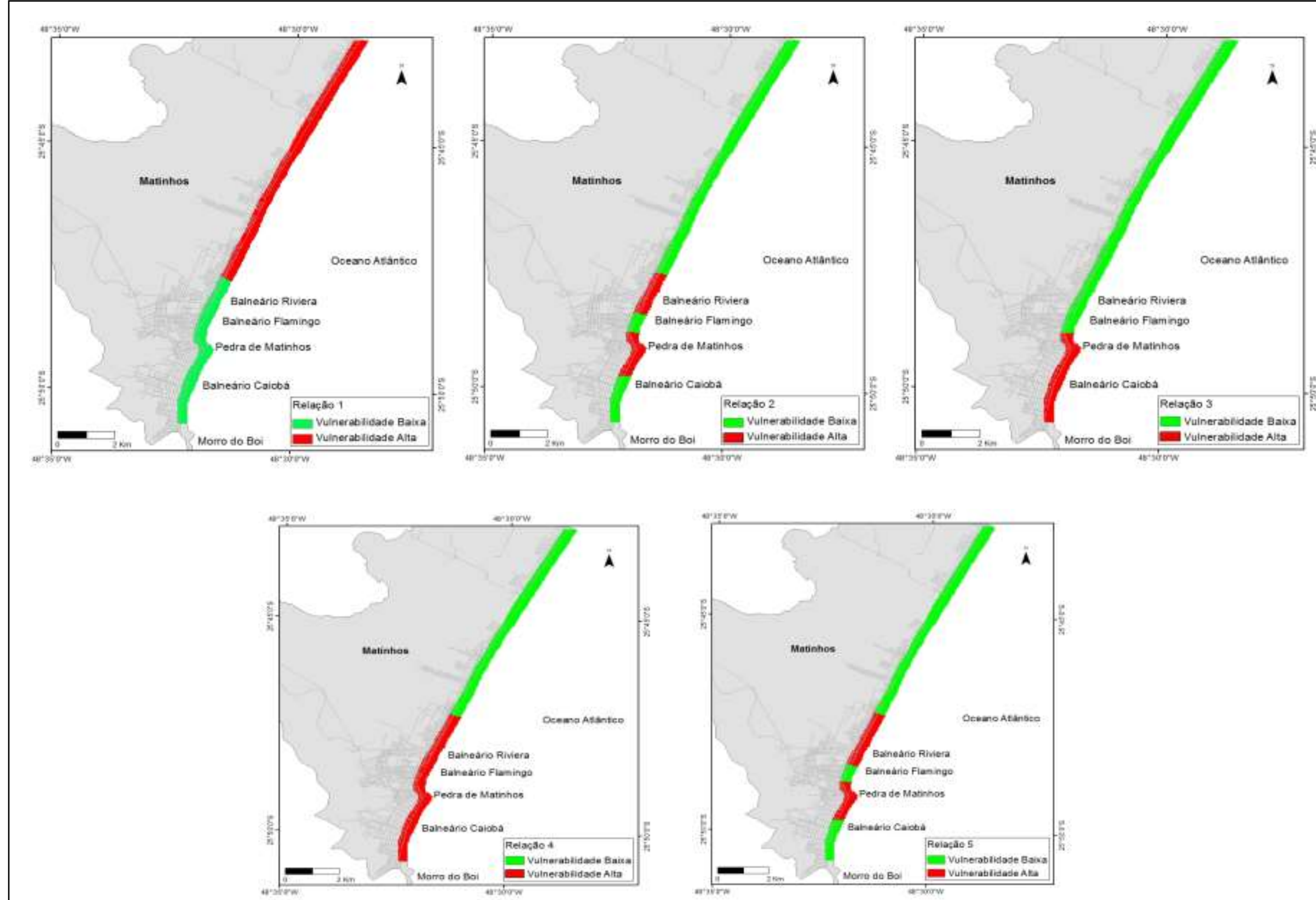

Figura 7: Mapas de vulnerabilidade à erosão costeira. 


\section{CONCLUSÕES}

Neste trabalho foi utilizada uma metodologia para o mapeamento da vulnerabilidade da zona costeira aos processos erosivos, baseado no uso de indicadores e análise espacial dos dados. Este método classificou os trechos norte e central do município de Matinhos como menos vulneráveis à erosão. A maior vulnerabilidade foi encontrada no Balneário Caiobá, Balneários Riviera e Flamingo, justamente onde ocorreram as obras de proteção costeira e onde a urbanização apresentou-se mais consolidada. Com isso, conclui-se que o método aplicado obteve sucesso nos resultados e pode ser aplicado nos ambientes praiais com boa chance de resultados significativos.

Quanto aos sangradouros, apesar de serem considerados potencializadores de processos erosivos, por transportarem sedimentos em direção ao mar, não evidenciaram um agravamento dos processos na área estudada. De acordo com as relações feitas, áreas onde os sangradouros estão mais concentrados foram consideradas com baixa vulnerabilidade (Relação \#1). Com os resultados obtidos nas relações \#2, \#3, \# 4 e \#5 foi possível verificar que a ocupação inadequada sobre a orla influenciou de maneira efetiva na vulnerabilidade aos processos de erosão costeira, corroborando com estudos realizados por Angulo (1993; 2000). Apesar de na relação \#2 a urbanização não ter sido um indicador considerado na avaliação, as obras costeiras estão ligadas à urbanização, pois surgem como uma tentativa de contenção de processos agravados pela ocupação indevida.

Dessa maneira, esta pesquisa apresentou uma metodologia prática com a aplicação de indicadores e uma ferramenta de análise espacial que contribuiu para estudos de vulnerabilidade à erosão costeira e, além disso, produziu resultados importantes que podem ser utilizados na elaboração de planos diretores, zonas de proteção ambiental e outros instrumento de planejamento da zona costeira paranaense.

Para eliminar as incertezas sobre o potencial erosivo dos sangradouros faz-se necessário realizar monitoramentos mensais e que incluam análise de perdas de sedimentos localmente, e também a realização de amostragens de 
VULNERABILIDADE AOS PROCESSOS EROSIVOS NO LITORAL DO PARANÁ ESTABELECIDO PELA APLICAÇÃO DA ANÁLISE MULTICRITÉRIOS

sedimentos da zona de espraiamento até a duna frontal. Além disso, é importante incluir outros indicadores hidrodinâmicos e geomorfológicos para resultados mais consistentes com relação às possíveis zonas de erosão da praia, não somente as com estágio avançado.

\section{REFERÊNCIAS}

ALVES, L. C. Identificação de Células de Deriva Longitudinal Litorânea através do Mapeamento Sedimentológico das Praias do Município de Pontal do Paraná, PR. Monografia (Graduação em Oceanografia). CEMUFPR.Pontal do Paraná.53p. 2011.

ANGULO R. J. Geologia da Planície Costeira do Estado do Paraná. 1992. Tese de Doutoramento, Instituto de Geociências, Universidade de São Paulo, São Paulo, 334 p.

ANGULO, R.J. Variações na linha de costa no Paraná nas últimas quatro décadas. Boletim Paranaense de Geociências, Curitiba, v. 41, p. 52-72.1993.

ANGULO, R. J. As Praias do Paraná: Problemas Decorrentes de uma Ocupação Desordenada. Revista Paranaense de Desenvolvimento, Curitiba, n. 99, p. 97-103,jul./dez. 2000.

ANGULO R. J. Mapa do Cenozóico do litoral do Estado do Paraná. Boletim Paranaense de Geociências, Curitiba, 55, p.25-42. 2004.

ANGULO,R. J.; ANDRADE J. J. Viabilidade de controle de erosão nas praias de Caiobá e Guaratuba. IPARDES, Curitiba,65 p. 1982.

ANGULO, R.J.; ARAÚJO, A.D. Classificação da costa paranaense com base na sua dinâmica, como subsídio à ocupação da orla litorânea. Boletim Paranaense de Geociências, Curitiba, v. 44, p. 7-17. 1996.

ANGULO R. J.; SOARES C. R. Beach Profile Variations Between 1981 And 1993 In Southern Coast Of Parana State. Boletim Paranaense de Geociências, Curitiba, v.42, p. 203-215. 1994

BIGARELLA, J.J. Contribuição ao Estudo da Planície Litorânea do Estado do Paraná. Arquivos de Biologia e Tecnologia. v.1. pp 75-111. 1946.

BIGARELLA, J.J; BEKER, R.D.;DE MATOS, D.J.;WENER, A. A Serra do mar e a porção oriental do estado do Paraná. Um problema de segurança ambiental e nacional (contribuição à geografia, geologia e ecologia regional). Governo do Estado do Paraná, Secretaria de Estado do 
VULNERABILIDADE AOS PROCESSOS EROSIVOS NO LITORAL DO PARANÁ ESTABELECIDO PELA APLICAÇÃO DA ANÁLISE MULTICRITÉRIOS

Planejamento - Associação de Defesa e Educação Ambiental (ADEA). Curitiba, 248p. 1978.

BIRD, E. C. E. Coastline Changes. New York: John Wiley, 1985.

BOAK, E.H.; TURNER, I.L., Shoreline Definition and Detection: A Review. Journal of Coastal Research,21(4), 688-703. West Palm Beach (Florida), ISSN 0749-0208. 2005.

CHANG, Y.H., SCRIMSHAW, M.D., LESTER, J.N. A revised Grain-Size Trend Analysis program to define net sediment transport pathways. Computers \& Geosciences, v. 27, p.109-114, 2001.

ESTEVES, L.S.; VANZ, A.; SILVA, A.R.P.; PIVEL, M.A.G.; ERTHAL,S.; BARLETTA, R.C.; VRANJAC, M.P.; OLIVEIRA, U.R. Caracterização das obras de proteção costeira no balneário do Hermenegildo, RS, Brasil. VII Congresso da ABEQUA,Porto Seguro, BA, Brasil. 1999.

ESTEVES, L.S.; PIVEL, M.A.G.; SILVA, A.R.P.; BARLETTA, R.C.; VRANJAC, M.P.; OLIVEIRA, U. R.; VANZ, A. Beachfront owners perception of beach erosion along an armored shoreline in Southern Brazil. Porto Alegre: Pesquisa em Geociências. 27(2). 93-109. 2000.

FIGUEIREDO, S. A de; CALLIARI, L. J. Sangradouros: Distribuição Espacial, Variação Sazonal, Padrões Morfológicos e Implicações no Gerenciamento Costeiro. Porto Alegre: Gravel, nov.2005.

FOLK, R.L.; WARD, W.C. 1957. Brazos river bar: A study in the significance of grain size parameters. Journal of Sedimentary Petrology, 27 (1), 3-27.

GAO, S.; COLLINS, M. Net sediment transport patterns inferred from grain-size trends, based upon definition of "transport vectors". Sedimentary Geology. 81. p.47-60. 1992.

IBGE. Instituto Brasileiro de Geografia e Estatística. Censo Demográfico de 2010. Disponível em: <www.ibge.gov.br>.Acesso em: maio. 2014.

UM/ISDR. (Inter Agency Secretariat of the International Strategy for Disaster Reduction). Setting the scene-understanding disaster risk reduction. In: Living with the risk: A Global Review of disaster reduction initiatives. 01-33.2004.

ITCG, 2014. Instituto de Terras, Cartografia e Geociências. Fotografias Aéreas-Litoral. Disponível: < http://www.itcg.pr.gov.br>. Acesso em: abril. 2014. 
VULNERABILIDADE AOS PROCESSOS EROSIVOS NO LITORAL DO PARANÁ ESTABELECIDO PELA APLICAÇÃO DA ANÁLISE MULTICRITÉRIOS

KLEIN, A. H. F.; POletTE, M.; HOEFEL, F. ; DIEHL, F L ; CARVALHO, J. L. B.; SILVA, R. P.; SIEGLE, E.; ABREU, J G N ; SANTOS, M I F dos ; FACHIN, S. . Erosão costeira no litoral centro-norte de Santa Catarina: Possíveis causas e medidas mitigadoras. In: VII Congresso da ABEQUA. Porto Seguro: Associação Brasileira de Estudos do Quaternário, 1999. v. CD ROM.

LAMOUR, M. R.; DOMIT, C.; CATTANI, P. E. Análise espacial de ambientes estuarinos e costeiros: subsídio a estudos de caracterização física e ecológica. (em preparação.)

LANA, P. C.; MARONE, E.; LOPES, R. M.; MACHADO, E. C. The Subtropical Estuarine Complex of Paranaguá Bay, Brazil. In: Ecological Studies, Coastal Marine Ecosystems of Latin America. v.144,131-145 p.Springer-Verlag Berlin Heidelberg. 2001.

MARONE E.; GUIMARÃES, M. R.; PRATA JR., V.P.;KLINGENFUSS, M.S.;CAMARGO R. Caracterização física das Condições Oceanográficas, Meteorológicas e Costeiras das zonas Estuarinas da Baía de Paranaguá, PR. VI Congreso Latinoamericano de Ciencias del Mar. Mar del Plata, Argentina. 1995.

MUEHE, D. Erosão e Progradação do Litoral Brasileiro. Brasília: Ministério do Meio Ambiente. 476p. 2006.

NASCIMENTO, L. BITTENCOURT, A.C. da S.P.; SANTOS,A.N.;DOMINGUEZ, J.M.L.Potencial de prejuízos econômicos em função da densidade de urbanização e da sensibilidade à erosão costeira na Costa do Cacau, Bahia. Revista Brasileira de Geomorfologia, v.14, n.4, (Out-Dez) p.261-270, 2013.

NEMES, D. D. Caracterização das ondas de superfície na plataforma interna do estado do Paraná. Dissertação (Pós-graduação em Sistemas Costeiro e Oceânicos). UFPR. Pontal do Paraná. 130 p. 2011.

NEMES, D. D.; MARONE, E. Caracterização das ondas de superfície na plataforma interna do litoral do Estado do Paraná, Brasil. Boletim Paranaense de Geociências, v. 68-69, p.12-25. Curitiba. 2013.

OLIVEIRA, E.; DOURADO, M. Caracterização Sazonal do Vento na Baía de Paranaguá-PR. III Congresso Brasileiro de Oceanografia - Rio Grande - RS - Brasil. 2010.

PROJETO ORLA. Fundamentos para gestão integrada. Ministério do Meio Ambiente, Ministério do Planejamento, Orçamento e Gestão. - Brasília: MMA, 74 p. 2006. 
VULNERABILIDADE AOS PROCESSOS EROSIVOS NO LITORAL DO PARANÁ ESTABELECIDO PELA APLICAÇÃO DA ANÁLISE MULTICRITÉRIOS

PIERRI, N.; ANGULO, R.J.; SOUZA,M.C.,KIM, M.K. A ocupação do solo no litoral paranaense: condicionantes, conflitos e tendências. Desenvolvimento e Meio Ambiente, Curitiba: UFPR, v.13, p.137-167, 2006.

QUADROS, C. J. L. Variações morfológicas e volumétricas associadas à incidência de sistemas frontais em duas praias arenosas do litoral paranaense. Dissertação (Mestrado em Geologia) UFPR, Curitiba,57p. 2002.

RUDDORFF, F. M.; BONETTI, J. Avaliação da Suscetibilidade à erosão costeira de praias da llha de Santa Catarina. Braz. J. Aquat. Sci. Technol. 14(1): p.9-20, 2010.

SCHWARTZ, M.L. Encyclopedia of Coastal Science. Dordrecht: Springer.

SOUZA, C. R. G. As células de deriva litorânea e a erosão nas praias do Estado de São Paulo. Tese de Doutoramento em Geologia Sedimentar.Universidade de São Paulo, São Paulo. 359p.2v. 1997.

SOUZA, C. R. de G.; SOUZA FILHO, P. W. M.; ESTEVES, S. L.; VITAL, H. DILLENBURG, S.R.; PATCHINEELAM, S.M. \& ADDAD, J.E. Praias Arenosas e Erosão Costeira. In: Quaternário do Brasil. Holos, Editora, Ribeirão Preto (SP). p. 130-152. 2005.

SOUZA, C.R de G. A Erosão Costeira e os Desafios da Gestão Costeira no Brasil. Revista de Gestão Costeira Integrada. n.9 p17-37. 2009.

SOUZA, C. R. G.; HIRUMA, S. T., SALLUN, A. E. M., RIBEIRO, R. R., SOBRINHO, J. M. A. "Restinga": Conceitos e Empregos do Termo no Brasil e Implicações na legislação Ambiental. São Paulo: Instituto Geológico $104 p, 2008$.

WENTWORTH, C.K. A Scale of Grade and Class Terms of Clastic Sediments. The Journal of Geology,v.30,.pp.377-392, n.5,jul-agos.,1922.

VEIGA, F. A., ANGULO R. J., MARONE E., BRANDINI F. P. Características sedimentológicas da plataforma continental interna rasa na porção central do litoral paranaense. Boletim Paranaense de Geociências, Curitiba, 55:67-75 (CD-ROM ) 2004. 